\title{
The sensitivity of efficiency scores to input and other choices in stochastic frontier analysis: An empirical investigation
}

\author{
Quang Van Nguyen,,${ }^{\mathrm{a}, \mathrm{b}, \mathrm{c}^{*}}$ Sean Pascoe ${ }^{\mathrm{b}}$, Louisa Coglan ${ }^{\mathrm{a}}$ and Son Nghiem ${ }^{\mathrm{d}}$
}

a) Queensland University of Technology (QUT), School of Economics and Finance, 2 George Street, Brisbane, 4001, Queensland, Australia.

b) CSIRO Oceans and Atmosphere, Queensland Biosciences Precinct, 306 Carmody Road, St Lucia 4067 Australia

c) College of Economics, Technology and Fisheries, Ly Nhan Tong Street, Dinh Bang, Tu Son, Bac Ninh, Vietnam

d) Centre for Applied Health Economics, Griffith University, 170 Kessels Road, Nathan, Queensland 4111, Australia

* Corresponding author email: vinhquang82@gmail.com

ORCID: Quang Van Nguyen 0000-0002-0483-3857; Sean Pascoe 0000-0001-6581-2649; Louisa Coglan 0000-0001-5730-7845; Son Nghiem 0000-0002-2451-5290

\section{Acknowledgements}

The authors would like to thank the Australian Fisheries Management Authority (AFMA) for permission to use the logbook and boat registry data for this analysis. The authors would like to thank the Editor and the anonymous reviewers for useful comments on earlier drafts of the paper. 


\section{The sensitivity of efficiency scores to input and other choices in stochastic frontier analysis: An empirical investigation}

\section{Abstract}

Productivity and efficiency analysis have gained substantial attention in many industries over the last two decades, and stochastic frontier analysis has been one of the most popular analytical approaches. The abundant model choices in stochastic frontier analysis make it difficult to select the best option and compare studies. The main purpose of this study is to examine the sensitivity of technical and scale efficiency estimates to choices around input-output combinations, functional forms, distributional assumptions and estimation methods in stochastic frontier analysis, using data from an Australian fishery to illustrate these effects.

We estimated 252 stochastic frontier models using combinations of variable choice, functional form and distributional assumptions. A second stage analysis was conducted to examine the effects of model choices on statistical properties of technical and scale efficiency.

The results show that estimates of technical and scale efficiency are most sensitive to distributional assumptions and the choice of time effects. In particular, the assumption of timeinvariant efficiency produced significantly higher technical efficiency (20 percentage points) and scale efficiency ( 8 percentage points) scores than time-varying efficiency models in our analysis. We also find that the choice of fixed input variables can significantly affect the average efficiency estimates, by as much as 5 percentage points, but mean efficiency was not significantly affected by the choice of variable inputs.

Our findings suggest that caution should be taken when comparing findings of stochastic frontier studies, especially those applied to the fishery industry, using different distributional assumptions.

Keywords: Technical efficiency, scale efficiency, fisheries, sensitivity analysis, input variables, stochastic frontier analysis, choice of models.

JEL: Q22, C51, C21 


\section{Introduction}

The abundance of choices in stochastic frontier analyses in terms of input-output combinations, functional forms, and distributional assumptions often makes it empirically challenging to select the most appropriate model. This, in turn, may have implications for the efficiency estimates as well as key model parameters such as production elasticities. For example, Baccouche and Kouki (2003) found that efficiency estimates were highly sensitive to the assumptions about the distribution of the one-sided error term, although in their study were less sensitive to the choice of a functional form of the production frontier. In contrast, both Giannakas et al. (2003) and Bravo-Ureta et al. (2007) found that functional form choice can have a significant impact on the resultant efficiency scores, with Giannakas et al. (2003) also suggesting that the choice of a functional form may introduce bias into the estimated production elasticities.

In practice, choices as to which model to use and input-output combinations are often made based on data availability and study objectives. While alternative specifications are often tested, these rarely examine all possible model choices and data combinations. Undertaking a comprehensive sensitivity analysis is a potential solution. However, it is often time-consuming when there are potentially many options and not consider pragmatically feasible.

The impact of functional form and error distribution assumptions on efficiency scores has been previously considered in the literature. The impact of input choice - when there are potential alternative (and mutually excludable) inputs that can be used in the production frontier - on the resultant inefficiency distribution has not.

The stochastic production frontier model estimates the impact of changing input use on outputs produced. Two types of inputs are usually included in these models - fixed and variable.

Fixed inputs (e.g., factory size, land) do not vary with the level of outputs produced, at least in the short-run, while variable inputs (e.g., labour, materials), as the name implies, do vary with the quantity produced (Carlson 1939). Fixed inputs also effectively define the level of capital invested by the firm, while variable inputs represent the level of utilisation of this capital to produce the final level of output. Alternative measures of both fixed and variable inputs are often available. Each measure may not fully capture firm capital or capital utilisation, but including several measures may result in other issues, particularly multicollinearity. As a result, a choice as to which set of inputs to use in a stochastic production frontier model is necessary. 
The main objective of this study was to examine the sensitivity of technical efficiency and scale efficiency scores to different model choices, particularly the choice of different fixed and variable input measures, extending the previous studies of Baccouche and Kouki (2003), Giannakas et al. (2003) and Bravo-Ureta et al. (2007). We also consider the impact of input choice on the estimation of scale efficiency (Ray 1999). A better understanding of the sensitivity of model choice on efficiency estimates contributes to the confidence that can be had in the findings, given available model choices (Andersen 2002; Andersen 2005; Pascoe et al. 2003; Valdmanis 1992).

Fisheries offer a challenge to productivity and efficiency analyses as many are characterised by multiple inputs - many of which are highly correlated - and multiple outputs, requiring a number of assumptions as which to include. In addition, analysts are faced with multiple alternatives in terms of functional forms of the production frontier (e.g., translog, CobbDouglas) and efficiency distributional assumptions. Previous studies conducted in the fishing industry show that these latter assumptions can have a significant effect on the efficiency estimates (e.g. Andersen 2002; Herrero and Pascoe 2003; Sharp et al. 2004). However, to the best of our knowledge, there has been no previous study in the fishing industry that examines the sensitivity of efficiency and other key productivity-related measures to assumptions regarding input use. This study examines the sensitivity of technical and scale efficiency estimates to the choices of input combinations, assumptions on functional forms, and assumptions on efficiency distributions (including time effects).

\section{Efficiency analysis in the fishing industry}

Unlike many industries, fisheries are actively managed by governments to ensure their ongoing sustainability as well as achieve a range of economic and social objectives. For fisheries managed through effort controls (e.g., vessel numbers, days fished or gear controls; compared with output controls that limit catches) this also requires an understanding of efficiency changes over time. Furthermore, different management actions have different consequences for fleet size and structure. For example, programs to remove excess capacity from fisheries have often not been as successful as initially anticipated as usually only the least efficient vessels are removed (Holland et al. 1999; Pascoe et al. 2012b; Quijano et al. 2018). Similarly, controls on input use may also result in efficiency losses to the industry as well as direct productivity impacts. 
For these reasons, an understanding of efficiency distributions, and factors affecting efficiency and productivity, has been a key feature of fisheries economics research over recent decades. Empirical studies have applied both parametric and non-parametric approaches to estimate efficiency, capacity utilisation and the factors affecting these measures. Examples of parametric applications using Stochastic Frontier Analysis (SFA) (Aigner et al. 1977; Meeusen and van Den Broeck 1977) in fisheries include Alvarez and Schmidt (2006); Esmaeili (2006); Fousekis and Klonaris (2003); Innes and Pascoe (2008); Jeon et al. (2006); Kirkley et al. (1995); Kirkley et al. (1998); Kompas et al. (2004b); Lokina (2009); Pascoe et al. (2017a); Pascoe et al. (2013); Pascoe et al. (2017b); Quang et al. (2019); Quijano et al. (2018); Solís et al. (2013); Squires et al. (2003). Similarly, the non-parametric Data Envelopment Analysis (DEA) (Charnes et al. 1978) has been widely applied in fisheries. Examples include CastillaEspino et al. (2014); Espino et al. (2005); Idda et al. (2009); Lindebo et al. (2007); Maravelias and Tsitsika (2008); Pascoe and Herrero (2004); Rust et al. (2017); Thanh et al. (2014); Thøgersen and Pascoe (2014); Tingley and Pascoe (2005); Tingley et al. (2005); Yamazaki et al. (2018). Other examples are also provided in the Supplementary Information. In a recent review of applications, fisheries were identified as one of the top 13 sectors where DEA had been widely applied, and one of the top five sectors where SFA had been applied (Lampe and Hilgers 2015), highlighting the importance of the methods to informing management of the sector.

Both DEA and SFA methods have drawbacks and benefits (Walden 2006). Previous studies have shown that there is no consensus as to which method is best (Herrero 2005; MurilloZamorano 2004). The choice of method applied in each study largely depends on the main purpose of the study, the availability of data, the characteristics of the productions process, the number of outputs and the degree of stochasticity (Herrero 2005; Pascoe and Tingley 2007). However, given the relative importance of random variation in fisheries (e.g., due to weather, storms, and other random environmental factors), studies focusing on technical efficiency have mostly applied the SFA approach (Kirkley et al. 1995; Lokina 2009), whereas DEA has been used mostly in studies focusing on capacity and capacity utilisation fisheries (Pascoe and Tingley 2007).

Many fisheries are characterised by multi-output production due to their mixed-species nature. DEA is well suited to multi-output analyses, and most of the above DEA studies used this approach to capture this feature of the fishery. In SFA studies, a distance function approach can also be used to take into account multiple outputs (Géraldine et al. 2015). This approach 
has been applied in a number of studies (e.g., Fousekis 2002; Herrero 2005; Orea et al. 2005; Pascoe et al. 2012a; Pascoe et al. 2010; Solís et al. 2015a; Solís et al. 2015b; Solis et al. 2014; Thøgersen and Pascoe 2014), although most SFA studies have used an aggregated output measure (either catch or revenue).

Inputs into fishing can be broadly considered as either capital-related inputs (fixed inputs) or capital utilisation inputs (variable inputs). The choice of capital (fixed) input variables for efficiency analysis in fisheries is often based on the available data, the relevance of which may vary based on the characteristics of the fisheries (e.g. gillnet versus trawl fisheries) (Andersen 2002; Greenville et al. 2006). Some studies have used engine power to represent boat capital (Duy and Flaaten 2016; Greenville et al. 2006; Kompas et al. 2004a; Oliveira et al. 2016) while others have used boat size, often hull length or in some cases a combination of length and width representing the total "deck area" (Fousekis and Klonaris 2003; Ngoc et al. 2009; Pascoe et al. 2017b; Squires and Kirkley 1999). Other studies have also used volumetric measures, such as gross registered tonnage (GRT) (Jeon et al. 2006; Squires et al. 2003; Susilowati et al. 2005; Viswanathan et al. 2001), or the amount of fishing gear deployed (Duy and Flaaten 2016; Fousekis and Klonaris 2003; Kompas et al. 2004a; Lokina 2009; Rust et al. 2017). Other studies have used a composite index that included engine power and boat size (i.e., length and width of vessel's hull) and/or fishing gear to capture the level of capital stock invested and to avoid the problem of multicollinearity in the models (Greenville et al. 2006; Pascoe and Coglan 2002; Vestergaard et al. 2003).

Where multiple measures of the physical size of the boat (e.g., boat's length, width, GRT and engine power) are available, these variables are often highly correlated (i.e., bigger boats need bigger engines), so using more than one of these as a capital measure is problematic. Each individual input (e.g., length or GRT), however, provides an imprecise measure of the total level of capital employed in fishing.

Measures of capital utilisation are equally problematic. Common measures of fishing effort range from hours fished to just the presence/absence of fishing on a particular day (e.g. Duy and Flaaten 2016; Jamnia et al. 2015; Kirkley et al. 1995; Ngoc et al. 2009). Crew size has been used as a variable input in a number of studies (Kirkley et al. 1995; Kirkley et al. 1998; Ngoc et al. 2009; Van Nguyen et al. 2019), but this variable is often highly correlated with boat size as bigger boats have more crew members employed. Furthermore, for some fisheries such as trawl fisheries, the role of the crew may be more related to post-harvest activities; additional 
crew members might not help produce a higher catch but instead may be required to process the catch (sort, pack etc.) once landed on-board (Pascoe et al. 2003).

From the literature, there is no consensus about which type of measures of input is most appropriate to include in efficiency analysis of the fishery industry (Andersen 2002), and the implications of using different measures (based on availability) are also unclear. Generally, different studies use different types of input measures determined by the available data. In particular, data on the level of capital and labour used in fishing are relatively limited, and physical inputs such as engine power or length of vessel tend to be used as proxy measures of capital for fisheries production and efficiency estimation (Pascoe et al. 2003). This is likely to be a broader problem than just in fisheries; many other industries also have issues with correlated inputs and the choice of input for use in the empirical models can also affect their efficiency estimates.

As all of these measures only partially capture the set of inputs into fishing (ignoring for simplicity the inputs provided by the natural capital, the fish stock, which is a non-discretionary input), the choice of input (either deliberate or due to lack of alternatives) will affect the estimated production frontier and the subsequent estimate of inefficiency. Therefore, it is important to examine the sensitivity of technical efficiency to the choice of inputs used.

A summary of key papers in the fisheries technical efficiency literature is given in the Supplementary Information, noting the functional form and inputs used in the different models. Some empirical studies in the fishing industry have reported differences in the efficiency estimates as a result of using different model functional forms, estimation approaches (e.g. SFA or DEA), or distributional assumptions (e.g. Herrero 2005; Orea et al. 2005; Sharp et al. 2004). However, the impact of different input uses on the estimated efficiency scores has not been previously considered.

\section{Methods}

The analysis is applied to a single species fishery, with the output measure being catch volume. There are two measures of output that have been widely used in evaluating efficiency in fisheries, namely, catch weight and catch revenue. Catch weight is widely used for a singlespecies fishery while catch revenue is more commonly applied when fishers operate in multispecies fisheries and individual species have widely varying prices (Herrero and Pascoe 2003; Pascoe and Tingley 2007). 
The study applied a two-stage approach. First, efficiency scores were estimated for the case study fishery using a range of different stochastic production frontier models. Second, the derived efficiency scores were regressed against the model characteristics. This two-step procedure was adopted rather than the usual one-step approach (i.e. as per Battese and Coelli (1995)) as the objective of this study was to determine how the mean efficiency levels are affected by different assumptions regarding input use and model specifications (i.e. compare outputs of different models), and not to examine the key drives of efficiency within a given model.

\subsection{Stochastic frontier analysis}

The study applies the standard Stochastic Frontier Analysis (SFA) (Aigner et al. 1977; Meeusen and Broeck 1977) approach to the fishery case study, given as:

$$
\ln y_{i t}=f(\ln x)+v_{i t}-u_{i t}
$$

where $y$ is the amount of output produced by vessel $i$ at time $t, x$ is a vector of input variables, $u_{i t}$ is a one-sided error term $(u \geq 0)$ that indicates the level of inefficiency of the vessel $i$, and $v_{i t}$ is a random error term that is assumed to be independently and identically distributed (iid), $N\left(0, \sigma_{v}^{2}\right)$.

The technical efficiency (TE) of the $\mathrm{i}-t h$ fishing boat is specified by $T E_{i}=\exp \left(-u_{i}\right)$. The technical efficiency score ranges from zero to one, with a higher score indicating greater efficiency. When $u_{i}=0$, the $\mathrm{i}-t h$ vessel lies on the stochastic frontier and $\mathrm{TE}=1$. In contrast, a fishing boat is considered technically inefficient if $u_{i}>0$ as its production lies below the production possibility frontier.

Separating out the components of the combined error terms requires a distributional assumption about the inefficiency term to be imposed. Common distributional assumptions include the truncated normal (Aigner et al. 1977) and half-normal (Jondrow et al. 1982) distribution. In models with fixed-effects and random-effects estimators (Cornwell et al. 1990; Schmidt and Sickles 1984), no distributional assumption is imposed and $u_{i}$ are normalised as $\max \left(u_{i}\right)-u_{i}$.

Another model specification for the inefficiency component relates to how inefficiency changes over time. One commonly applied approach (Battese and Coelli 1992) specifies inefficiency as $u_{i t}=u_{i} e^{-\eta(t-T)}$, where $u_{i t}$ is inefficiency of $\mathrm{i}-t h$ vessel at time $t, T$ represents time periods (i.e., $u_{i t}=u_{i}$, when $t=\mathrm{T}$ ), and $\eta$ is an unknown scalar parameter to be estimated, 
measuring the rate of change in technical inefficiency over time. If $\eta>0, \eta=0$ and $\eta<0$ indicate that $u_{i t}$ decrease, remain unchanged or increase, respectively when $t$ increases.

Several different functional forms of the production frontier are also commonly employed, including the Cobb-Douglas (Douglas 1976; Zellner et al. 1966), translog (Christensen et al. 1973) and Fourier (Tsionas 2012).

In addition to technical efficiency, scale efficiency is a useful measure for assessing how the fleet structure may change over time. Scale efficiency is a measure as to how close a firm is to an "optimal" size, and it is likely that the fleet structure will converge more towards this optimal as adjustment takes place over time. Ray (1999) proposed that scale efficiency can be estimated from a translog functional form as: $S E_{i t}=e^{\left[\left(1-E_{i t}\right)^{2} / 2 B\right]}$, where $E_{i t}=\sum_{j} \beta_{k}+$ $\sum_{k} \beta_{j k} \log \left(x_{j k}\right)+\beta_{i j} t$; and $B=\sum_{k} \sum_{j} \beta_{j k}$ is the sum of estimated parameters of the production function; $\beta$ are parameters to be estimated; $x_{j k}$ are input combination; $t$ is the time trend.

Various estimators, including fixed-effects, random-effects and maximum likelihood can be used to estimate the unknown parameters of the stochastic frontier models. The presence of the efficiency component $\left(u_{i}\right)$ in the composite error terms is tested using the likelihood ratio test (Coelli et al. 2005). The likelihood ratio (LR) test was used to examine the different hypotheses imposed on the models. The test is defined by $L R=-2\left(L_{R}-L_{U}\right)$, where $L_{R}$ and $L_{U}$ are the restricted (null hypothesis: $u_{i}=0$ ) and unrestricted (alternative hypotheses: $\mathrm{u}_{i} \neq 0$ ) log-likelihood values. The log-likelihood of the null hypothesis was obtained from a generalised linear model estimator while the unrestricted log-likelihood value is obtained from stochastic frontier estimators. The LR value has a $\chi^{2}$ distribution with the number of degrees of freedom given by the number of the restriction (Coelli et al. 2005).

\subsection{Data}

Data used in this study were collected from the Australian Northern Prawn Fishery (NPF). The NPF is one of Australia's most valuable fisheries in terms of gross value product. The fishery consists of two main components; a banana prawn component that operates in the first half of the year and a tiger prawn component that operates in the second half. The banana prawn component is single-species focused, whereas the tiger prawn component is multi-species in nature, catching a range of other species in addition to tiger prawns. 
The fishery is managed using effort controls, and hence efficiency analysis has provided valuable information for its management. Previous efficiency studies of the banana prawn component include Kompas et al. (2004b) and Pascoe et al. (2018), while studies of the tiger prawn component include Pascoe et al. (2010) and Pascoe et al. (2012a).

The data for this study were derived from logbook and vessel registry information covering the period 2010 to 2015 , and relate to the single-species banana prawn component of the fishery. The data included daily catch and effort for each individual vessel, with the latter available as two different measures: total hours of operation (including both fishing and searching time) and hours trawled. These variables were aggregated into weekly values for each vessel, with a further measure of effort derived as the number of days fished each week. Other vessel characteristics, such as engine power $(\mathrm{kW})$ and vessel length $(\mathrm{m})$, were also available, and these were merged with the catch and effort data. A summary of the key vessel data is given in Table 1. While 52 licences are available for the fishery at any one time, over the period examined 62 different vessels reported fishing activity.

Table 1. Weekly data summary, banana prawn fishery 2010-2015

\begin{tabular}{lrrrrrr}
\hline & Min. & 1st Qu. & Median & Mean & 3rd Qu. & Max. \\
\hline Catch $(\mathrm{kg})$ & 111.0 & 4084.0 & 7704.0 & 9368.0 & 13075.0 & 37814.0 \\
Length $(\mathrm{m})$ & 16.8 & 21.8 & 22.3 & 22.7 & 24.1 & 29.2 \\
Engine power $(\mathrm{kW})$ & 262.0 & 342.0 & 410.0 & 397.5 & 450.0 & 526.0 \\
Hours trawled & 11.0 & 17.0 & 26.0 & 32.3 & 39.8 & 161.0 \\
Hours fished & 11.0 & 66.0 & 94.0 & 92.5 & 117.0 & 167.0 \\
Days fished & 1.0 & 5.0 & 6.0 & 5.9 & 7.0 & 7.0 \\
\hline
\end{tabular}

Fish stock is a crucial non-discretionary input in the fishery industry (Hannesson 1983). An index of banana prawn biomass change over the season and between years was estimated previously by Pascoe et al. (2018) and used in this study.

All data were logged and normalised (i.e., such that their mean values were zeros). Correlation between the logged variables is given in Table 2. Engine power and vessel length are highly correlated, so including both measures into a production function would be inappropriate. The relatively low correlation between hours trawled and days fished indicates the potential for measurement errors to affect the production function and subsequently efficiency estimate if the coarser measure (days fished) is used. 
Table 2. Correlation between key variables

\begin{tabular}{llllllll}
\hline & $\begin{array}{l}\text { Catch } \\
(\mathrm{kg})\end{array}$ & $\begin{array}{l}\text { Engine } \\
\text { Power } \\
(\mathrm{kW})\end{array}$ & $\begin{array}{l}\text { Length } \\
(\mathrm{m})\end{array}$ & $\begin{array}{l}\text { Days } \\
\text { fished }\end{array}$ & $\begin{array}{l}\text { Hours } \\
\text { fished }\end{array}$ & $\begin{array}{l}\text { Hours } \\
\text { Trawled }\end{array}$ & $\begin{array}{l}\text { Stock } \\
\text { index }\end{array}$ \\
\hline Catch $(\mathrm{kg})$ & 1.00 & & & & & & \\
Engine Power $(\mathrm{kW})$ & 0.09 & 1.00 & & & & & \\
Length (m) & 0.04 & 0.76 & 1.00 & & & & \\
Days fished & 0.22 & -0.01 & -0.03 & 1.00 & & & \\
Hours fished & 0.05 & 0.01 & 0.08 & 0.59 & 1.00 & & \\
Hours Trawled & -0.02 & 0.06 & 0.10 & 0.24 & 0.28 & 1.00 & \\
Stock index & 0.62 & -0.15 & -0.17 & 0.12 & -0.08 & -0.19 & 1.00 \\
\hline
\end{tabular}

\subsection{Functional forms and input combinations}

Overall, 252 stochastic frontier models were estimated from 6 input combinations (Table 3), three functional forms (translog, Fourier, and Cobb-Douglas) and 14 different inefficiency distributions (Table 4). The three functional forms were selected based on their popularity in the literature (Huang and Lai 2012; Parmeter et al. 2019).

Table 3. Input combinations

\begin{tabular}{cccc}
\hline & $\begin{array}{c}\text { Fixed input } \\
\text { (Capital) }\end{array}$ & $\begin{array}{c}\text { Variable input } \\
\text { (Utilisation) }\end{array}$ & $\begin{array}{c}\text { Non-discretionary } \\
\text { (Fish stock) }\end{array}$ \\
\hline 1 & Engine power & Hours trawled & Biomass index \\
2 & Engine power & Hours fished & Biomass index \\
3 & Engine power & Days fished & Biomass index \\
4 & Vessel length & Hours trawled & Biomass index \\
5 & Vessel length & Hours fished & Biomass index \\
6 & Vessel length & Days fished & Biomass index \\
\hline
\end{tabular}

Table 4. Inefficiency distributions

\begin{tabular}{lllll}
\hline & Authors & Estimator* & Distributions & Time effects \\
\hline 1 & Schmidt and Sickles (1984) & FE & Fixed effects & Invariant \\
2 & Schmidt and Sickles (1984) & GLS-RE & Random effects & Invariant \\
3 & Pitt and Lee (1981) & ML & Half normal & Invariant \\
4 & Battese and Coelli (1988) & ML & Truncated normal & Invariant \\
5 & Cornwell, Schmidt \&Sickles (1990) & FE & Fixed effects & Varying \\
6 & Kumbhakar (1990) & ML & Half normal & Varying \\
7 & Battese and Coelli (1992) & ML & Truncated normal & Varying \\
8 & Battese and Coelli (1995) & ML & Truncated normal & Varying \\
9 & Greene (2005) & ML-FE & Exponential & Varying \\
10 & Greene (2005) & ML-FE & Truncated normal & Varying \\
11 & Greene (2005) & ML-FE & Half normal & Varying \\
12 & Greene (2005) & ML-RE & Exponential & Varying \\
13 & Greene (2005) & ML-RE & Truncated normal & Varying \\
14 & Greene (2005) & ML-RE & Half normal & Varying \\
\hline
\end{tabular}

*FE=fixed-effects, $\mathrm{RE}=$ random-effects; $\mathrm{ML}=$ maximum likelihood, GLS=generalised least squared 


\subsection{Regression analysis and model averaging}

Ordinary Least Squares (OLS) was used to examine the relationship between the different model assumptions and the summary statistics (e.g., means and standard deviation of the efficiency scores) of the 252 estimated stochastic frontier models. We use ordinary least squares with robust standard errors in this second stage analysis based on findings from previous studies (Hoff 2007; McDonald 2009), which suggest that for fractional data like efficiency scores, OLS with robust standard errors is a consistent estimator.

We also apply the model-average estimator proposed by Huang and Lai (2012), which is a weighted average of the 252 models, to present the aggregate technical efficiency and scale efficiency. Huang and Lai (2012) recommended using Akaike, Bayesian and Takeuchi information criteria as weights for the model average, with the weights given by: $\pi_{i}^{I C}=$ $\frac{\exp \left(-0.5 \times \Delta I C_{i}\right)}{\sum_{j} \exp \left(-0.5 \times \Delta I C_{j}\right)}$, where $\Delta I C_{i}=I C_{i}-I C_{\min }$ and IC = information criterion (AIC, BIC). We also use a simple option of equal weights (1/number of models) to calculate model-averaged efficiency scores for the sensitivity analysis. While other model-averaging estimators are available, Parmeter et al. (2019) found that as sample size and the amount of variation explained by inefficiency increased, the differences between these different modelling approaches decreased.

\section{Results and Discussions}

\subsection{Summary statistics}

A purported advantage of SFA approaches over non-parametric approaches such as DEA is their ability to separate inefficiency from random error in the error term. A measure of the amount of total variation in the error term explained by inefficiency is the gamma parameter, derived as the variance in the estimated inefficiency distribution divided by the overall residual variation. We found that different model specifications attributed markedly different levels of variance to the inefficiency component. From the distribution of the signal-to-noise parameter Gamma (Figure 1), the range varied substantially depending on the model specification. Generally, inefficiency comprised a larger proportion of total error for the Fourier functional form, with this being fairly consistent across other assumptions. In contrast, the contribution of inefficiency given the Cobb-Douglas functional form was the most variable. However, the 
mean estimates from each functional form, represented as white diamonds in Figure 1, were similar.

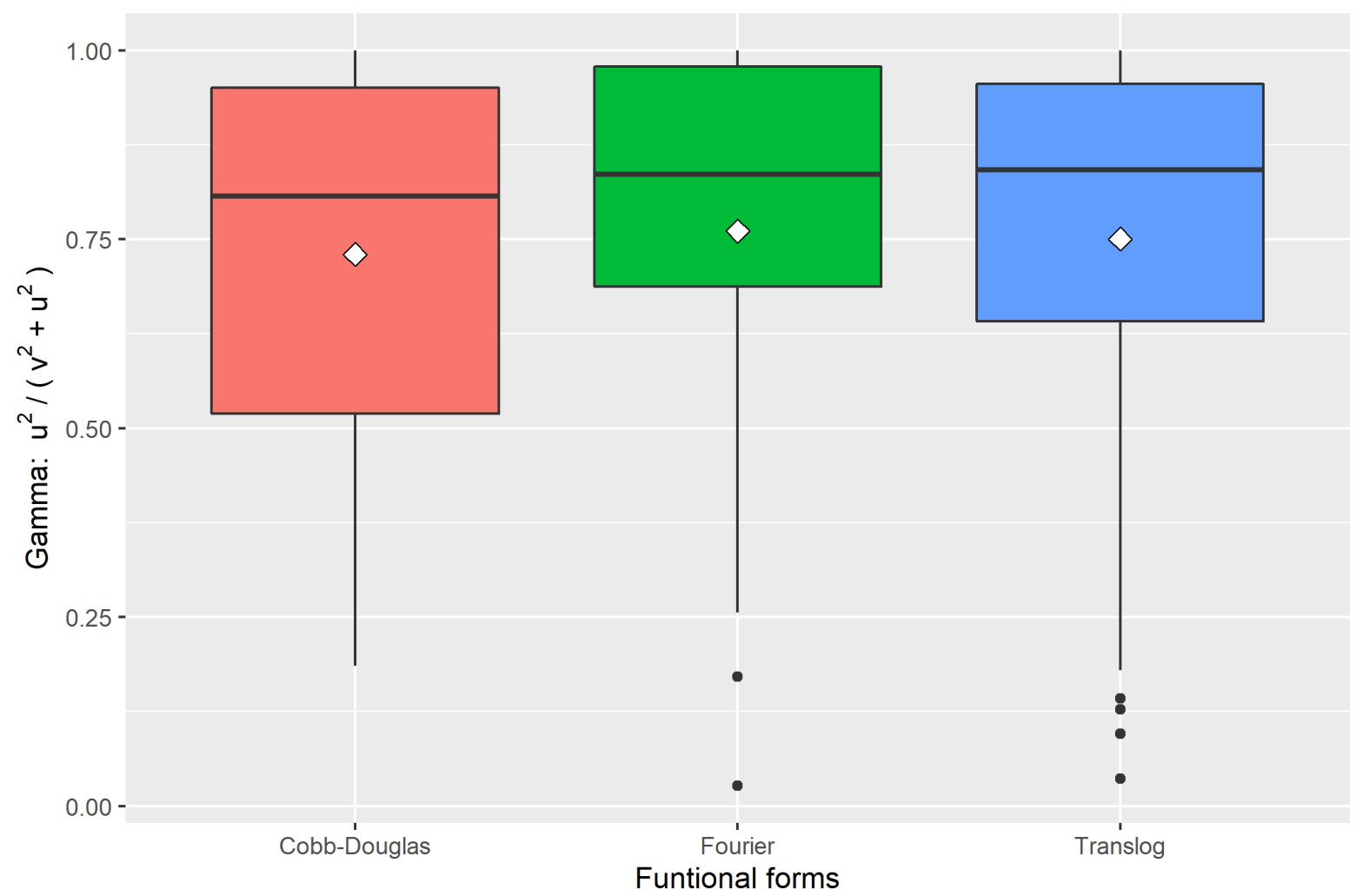

Figure 1. Distribution of Gamma by functional forms

The likelihood ratio test rejected, at the $5 \%$ significant level, the null hypothesis that $u_{i}=0$ (i.e., no efficiency) in 239 out of 252 models (95\% of models). Conversely, for $5 \%$ of the models, inefficiency was estimated to be zero.

The means and $95 \%$ confidence intervals of the technical and scale efficiency scores from all models are presented in Table 5, averaged for models using each particular specification. The truncated-normal distribution assumption was associated with the highest average technical efficiency score and the second-highest scale efficiency scores. In contrast, the half-normal distribution was associated with the lowest average technical efficiency scores.

For scale efficiency, the exponential distribution was associated with the lowest average score and the $95 \%$ confidence intervals show significant differences with models using truncated normal assumption and fixed/random effects. 
Table 5. Summary statistics by model combinations

\begin{tabular}{|c|c|c|}
\hline & Technical efficiency & Scale efficiency \\
\hline \multicolumn{3}{|l|}{ Input choice } \\
\hline \multicolumn{3}{|l|}{ Capacity measure } \\
\hline - Hull length & $0.61(0.58,0.65)$ & $0.77(0.74,0.80)$ \\
\hline - Engine & $0.66(0.63,0.69)$ & $0.73(0.69,0.77)$ \\
\hline \multicolumn{3}{|l|}{ Utilisation measure } \\
\hline - Hours trawled & $0.64(0.60,0.68)$ & $0.72(0.67,0.77)$ \\
\hline - Hours fished & $0.63(0.58,0.67)$ & $0.73(0.67,0.78)$ \\
\hline - Days fished & $0.65(0.61,0.69)$ & $0.80(0.77,0.83)$ \\
\hline \multicolumn{3}{|l|}{ Efficiency Distribution } \\
\hline Fixed/random effects & $0.61(0.57,0.65)$ & $0.81(0.75,0.86)$ \\
\hline Half-normal & $0.57(0.54,0.59)$ & $0.73(0.66,0.80)$ \\
\hline Truncated normal & $0.66(0.62,0.70)$ & $0.77(0.74,0.80)$ \\
\hline Exponential & $0.62(0.62,0.63)$ & $0.61(0.51,0.70)$ \\
\hline \multicolumn{3}{|l|}{ Time effects } \\
\hline - Varying & $0.61(0.58,0.64)$ & $0.72(0.69,0.76)$ \\
\hline - Invariant & $0.71(0.68,0.75)$ & $0.82(0.79,0.85)$ \\
\hline \multicolumn{3}{|l|}{ Functional forms } \\
\hline Translog & $0.65(0.61,0.69)$ & $0.76(0.72,0.80)$ \\
\hline Cobb-Douglas & $0.61(0.56,0.65)$ & N/A \\
\hline Fourier & $0.66(0.62,0.70)$ & $0.74(0.70,0.78)$ \\
\hline
\end{tabular}

Models that use engine capacity as a proxy for vessel capital (reflecting vessel capacity) were associated with higher average technical efficiency score (0.66) than those using vessel length as a capacity proxy, but the confidence intervals are overlapping. Scale efficiency scores show the reverse; that more vessels were closer to their optimal length than optimal engine power, although the confidence intervals of the two specifications again overlap.

The 95\% confidence intervals indicate that the technical efficiency and scale efficiency scores were not significantly different given the different measures of fishing time (fishing effort) or functional forms. Models with time-invariant efficiency component were associated with higher average technical efficiency compared with that of time-varying efficiency models $(0.71$ vs 0.61$)$. Scale efficiency scores were also significantly higher for time-invariant models (0.82 vs 0.72$)$.

Overall, the means of the efficiency scores in this study did vary given different distributional assumption, inputs used and time effects, although the magnitudes of the differences were small. However, the group summary in Table 5 does not control for any other covariates. This issue is mitigated by using regression analysis. 


\subsection{Regression analysis and model averaging}

Results from the regression analysis are presented in Table 6, where it can be seen that some model specifications resulted in significantly different technical and scale efficiency scores. In particular, the assumption of time-invariant efficiency produced significantly higher technical efficiency (20 percentage points) and scale efficiency ( 8 percentage points) scores than timevarying efficiency models. Different distributional assumptions also result in significantly different efficiency scores. For example, the model with an exponential distribution assumption produces significantly higher technical efficiency than that assuming a half-normal distribution. In contrast, models imposing fixed/random effects produce technical efficiency scores lower than those of the half-normal models. Similarly, with respect to scale efficiency, models with exponential assumption produce the lowest average efficiency score while models with truncated-normal assumption produce the highest average.

Table 6. Regression analysis results

\begin{tabular}{|c|c|c|c|c|c|c|}
\hline \multirow[b]{2}{*}{ Covariates } & \multicolumn{3}{|c|}{ Technical efficiency } & \multicolumn{3}{|c|}{ Scale efficiency } \\
\hline & Coef. & $\begin{array}{l}\text { Robust } \\
\text { Std. err }\end{array}$ & & Coef. & $\begin{array}{l}\text { Robust } \\
\text { Std. err }\end{array}$ & \\
\hline Constant & 0.517 & 0.026 & $* * *$ & 0.591 & 0.051 & *** \\
\hline \multicolumn{7}{|l|}{ Capital } \\
\hline - Length & Base & & & Base & & \\
\hline - Engine & 0.049 & 0.023 & $* *$ & -0.039 & 0.026 & \\
\hline \multicolumn{7}{|l|}{ Capital utilisation } \\
\hline - Hours trawled & Base & & & Base & & \\
\hline - Hours fished (incl. search) & -0.015 & 0.029 & & 0.005 & 0.036 & \\
\hline - Days fished & 0.006 & 0.027 & & 0.077 & 0.027 & $* * *$ \\
\hline \multicolumn{7}{|l|}{ Functional form } \\
\hline - Cobb-Douglas & Base & & & Base & & \\
\hline - Translog & 0.042 & 0.028 & & 0.018 & 0.026 & \\
\hline - Fourier & 0.049 & 0.029 & $*$ & N/A & & \\
\hline \multicolumn{7}{|l|}{ Time effects } \\
\hline - Varying & Base & & & Base & & \\
\hline - Time-invariant & 0.202 & 0.026 & $* * *$ & 0.077 & 0.028 & $* * *$ \\
\hline \multicolumn{7}{|l|}{ Distributional assumption } \\
\hline - Fixed/random effects & -0.158 & 0.035 & $* * *$ & 0.123 & 0.061 & $* *$ \\
\hline - Truncated normal & 0.046 & 0.028 & & 0.146 & 0.050 & $* * *$ \\
\hline - Exponential & 0.054 & 0.014 & $* * *$ & Base & & \\
\hline - Half normal & Base & & & 0.125 & 0.058 & ** \\
\hline R squared & 0.18 & & & 0.19 & & \\
\hline \multicolumn{7}{|l|}{ Ramsey test: } \\
\hline - test-statistics & 0.31 & & & 2.16 & & \\
\hline - $\quad(p$-value $)$ & $(0.82)$ & & & $(0.10)$ & & \\
\hline Observations & 252 & & & 168 & & \\
\hline
\end{tabular}

Note: $* * * 1 \%$ significance level; $* * 5 \%$ significance level; $* 10 \%$ significance level 
The choice of fixed inputs used in the production frontier can also affect the resultant estimated technical efficiency. Fishing capacity measured as engine power resulted in a higher mean technical efficiency (by five percentage points) compared with models that used vessel length. In contrast, the choice of variable inputs was found to have no significant effects on technical efficiency but did affect scale efficiency estimates. This finding suggests that estimates of optimal vessel capital (length or engine power) depend on the measurement of variable inputs used. The choice of functional form also remains insignificant to both technical and scale efficiency estimates.

Model-average results (following the approach proposed by Huang and Lai (2012)) were generally robust to the choice of information criteria used (Figure 2). Weights based on both AIC and BIC resulted in similar mean efficiency scores (white diamonds in Figure 2), with the interquartile range of technical efficiency being slightly wider when using BIC. Using the naïve equal weight option resulted in a narrower inter-quartile range and more symmetrical distribution (i.e. means are closer to the medians) for technical efficiency. One possible explanation is that the models with a low AIC or BIC (i.e. a "better fit" to the data and hence have higher weights) also had higher variations in technical efficiency.

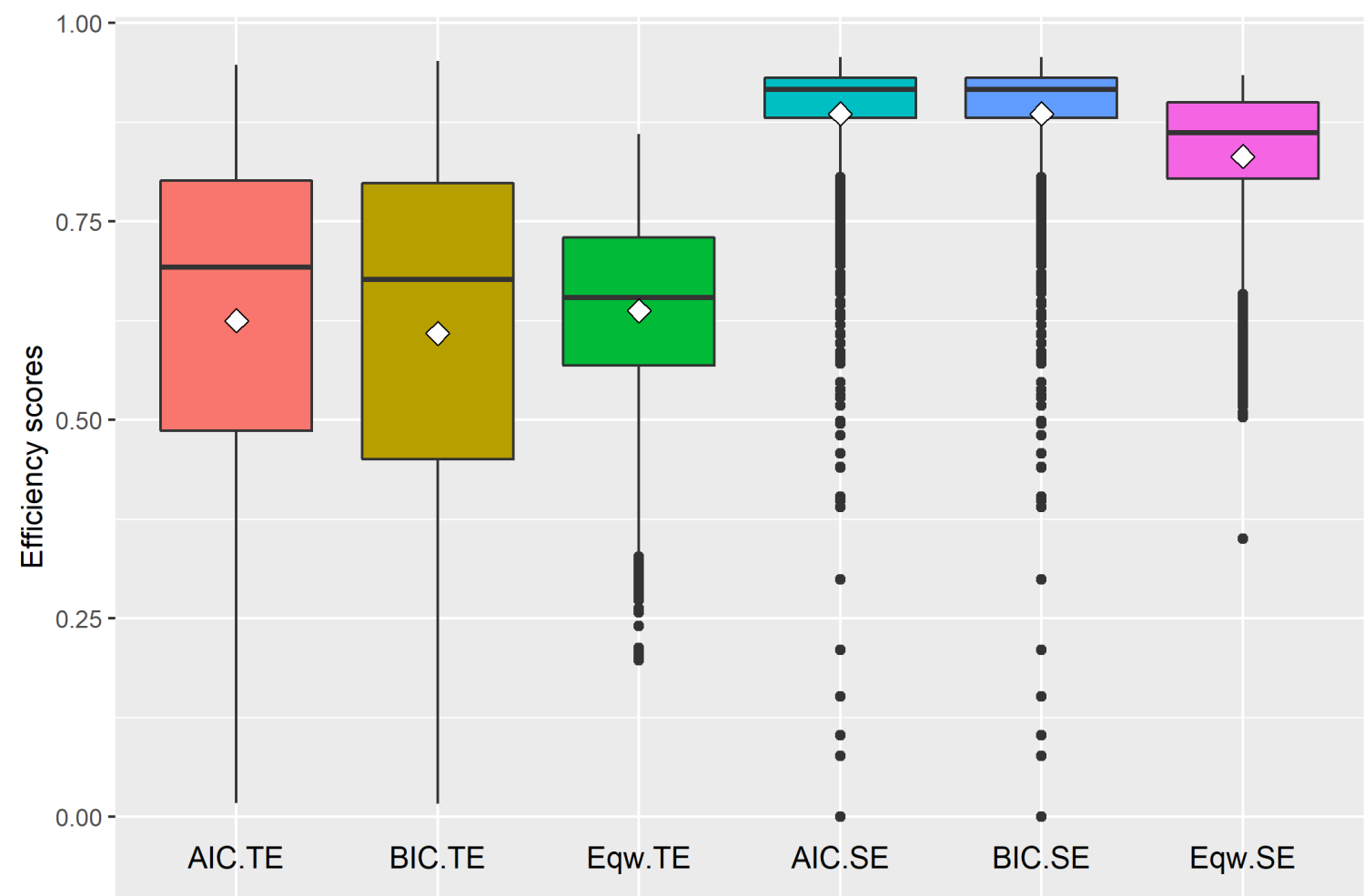

Figure 2. Model-average summary of efficiency scores using different weightings $\mathrm{AIC}=\mathrm{AIC}$ weights; $\mathrm{BIC}=\mathrm{BIC}$ weights, Eqw=equal weights, TE=technical efficiency, SE=Scale efficiency 


\section{Conclusions}

To the best of our knowledge, this study is the first systematic examination of the effects of model choices on stochastic frontier estimates in the fishery industry. We found that results of panel data stochastic frontier models may be sensitive to the choice of distributional assumption and time-effects. This finding is in line with a previous sensitivity analysis by Baccouche and Kouki (2003), which also found that results of the stochastic frontier analysis are sensitive to distributional assumption and not affected substantially by choice of functional form.

The lower sensitivity to variable input choices found is of particular relevance to fisheries studies, as data are not always collected in a consistent manner between fisheries. Fishing effort is often measured only in terms of the number of days fished for most Australian (and international) fisheries, with relatively few fisheries having the finer detail of hours fished available as for this study, and fewer still having information on search time as well as fishing time. These differences in measures had no significant impact on technical efficiency. However, the choice of variable input did have some impact on the scale efficiency estimates; with the more coarse measure (number of days fished) beings associated with higher scale efficiency measures.

The capacity related measure (the fixed inputs) were found to have a significant impact on the technical efficiency estimates, although there is no a priori means to assess which measure may be more appropriate for the fishery. As noted by Parmeter et al. (2019), there is often little in the way of theoretical guidance to determine which different variables best represent the production structure. Where multiple measures are available, such as in this study, model averaging approaches (Huang and Lai 2012; Parmeter et al. 2019) may be appropriate to provide a more robust estimate of technical efficiency and its distribution in the face of this uncertainty.

\section{Compliance with ethical standards}

Research involving Human Participants: All data for the project were collected by AFMA as a requirement under the Australian Fisheries Management Act 1991 for use in informing fisheries management. No primary data were collected by the Authors. 
Funding: The study received no financial support. The work was undertaken as part of $\mathrm{PhD}$ research by the first author.

Conflict of interest: The authors declare that they have no conflict of interest.

\section{Reference}

Aigner D, Lovell CAK, Schmidt P (1977) Formulation and estimation of stochastic frontier production function models Journal of Econometrics 6:21-37

Alvarez A, Schmidt P (2006) Is skill more important than luck in explaining fish catches? Journal of Productivity Analysis 26:15-25 doi:10.1007/s11123-006-0002-x

Andersen JL (2002) Using different inputs and outputs to estimate technical efficiency in fisheries: An application to Danish Seiners in the North Sea and Skagerrak. University of Copenhagen, Denmark

Andersen JL (2005) The Inclusion of Stocks in Multi-species Fisheries: The Case of Danish Seiners Marine Resource Economics 20:163-184 doi: https://doi.org/10.1086/mre.20.2.42629467

Baccouche R, Kouki M (2003) Stochastic production frontier and technical inefficiency: A sensitivity analysis Econometric Reviews 22:79-91

Battese GE, Coelli TJ (1988) Prediction of Firm-Level Technical Efficiencies with a Generalised

Battese GE, Coelli TJ (1992) Frontier Production Functions, Technical Efficiency and Panel Data: With Application to Paddy Farmers in India Journal of Productivity Analysis 3:153-169 doi:10.1007/BF00158774

Battese GE, Coelli TJ (1995) A model for technical inefficiency effects in a stochastic frontier production function for panel data Empirical Economics 20:325-332

Bravo-Ureta BE, Solís D, Moreira López VH, Maripani JF, Thiam A, Rivas T (2007) Technical efficiency in farming: a meta-regression analysis Journal of Productivity Analysis 27:57-72 doi:10.1007/s 11123-006-0025-3

Carlson S (1939) Study on the pure theory of production. P.S. King, London

Castilla-Espino D, García-del-Hoyo JJ, Metreveli M, Bilashvili K (2014) Fishing capacity of the southeastern Black Sea anchovy fishery Journal of Marine Systems 135:160-169

Charnes A, Cooper WW, Rhodes E (1978) Measuring the efficiency of decision making units European Journal of Operational Research 2:429-444

Christensen LR, Jorgenson DW, Lau LJ (1973) Transcendental logarithmic production frontiers Review of Economics and Statistics 55:28-45

Coelli TJ, Battese GE, Donnell CJ, Rao DSP (2005) An Introduction to Efficiency and Productivity Analysis. vol Book, Whole. Springer Science + Business Media, New York, USA

Cornwell C, Schmidt P, Sickles RC (1990) Production frontiers with cross-sectional and timeseries variation in efficiency levels Journal of Econometrics 46:185-200 doi:http://dx.doi.org/10.1016/0304-4076(90)90054-W 
Douglas PH (1976) The Cobb-Douglas Production Function Once Again: Its History, Its Testing, and Some New Empirical Values Journal of Political Economy 84:903-915 doi: $10.2307 / 1830435$

Duy NN, Flaaten O (2016) Efficiency analysis of fisheries using stock proxies Fisheries Research 181:102-113 doi:http://dx.doi.org/10.1016/j.fishres.2016.04.006

Esmaeili A (2006) Technical efficiency analysis for the Iranian fishery in the Persian Gulf ICES Journal of Marine Science 63:1759-1764

Espino DC, Del Hoyo JJ, xc, Garc, xcd, Sharp BMH (2005) Capacity and Capacity Utilisation of the "Voracera" Fleet in the Strait of Gibraltar Marine Resource Economics 20:367384

Fousekis P (2002) Distance vs. ray functions: an application to the inshore fishery of Greece Marine resource economics 17:251-267

Fousekis P, Klonaris S (2003) Technical efficiency determinants for fisheries: a study of trammel netters in Greece Fisheries Research 63:85-95

Géraldine H, Henningsen A, Jensen U (2015) A Monte Carlo study on multiple output stochastic frontiers: a comparison of two approaches Journal of Productivity Analysis 44:309-320 doi:10.1007/s11123-014-0416-9

Giannakas K, Tran KC, Tzouvelekas V (2003) Predicting technical effciency in stochastic production frontier models in the presence of misspecification: a Monte-Carlo analysis Applied Economics 35:153-161 doi:10.1080/0003684022000015964

Greene W (2005) Reconsidering heterogeneity in panel data estimators of the stochastic frontier model Journal of econometrics 126:269-303

Greenville J, Hartmann J, MacAulay TG (2006) Technical efficiency in input-controlled fisheries: The NSW Ocean Prawn Trawl Fishery Marine Resource Economics 21:159179 doi:https://doi.org/10.1086/mre.21.2.42629502

Hannesson R (1983) Bioeconomic Production Function in Fisheries: Theoretical and Empirical Analysis Canadian Journal of Fisheries and Aquatic Sciences 40:968-982 doi:10.1139/f83-123

Herrero I (2005) Different approaches to efficiency analysis. An application to the Spanish Trawl fleet operating in Moroccan waters European Journal of Operational Research $167: 257-271$

Herrero I, Pascoe S (2003) Value versus Volume in the Catch of the Spanish South-Atlantic Trawl Fishery Journal of Agricultural Economics 54:325-341 doi:https://doi.org/10.1111/j.1477-9552.2003.tb00066.x

Hoff A (2007) Second stage DEA: Comparison of approaches for modelling the DEA score European Journal of Operational Research 181:425-435 doi:10.1016/j.ejor.2006.05.019

Holland D, Gudmundsson E, Gates J (1999) Do fishing vessel buyback programs work: A survey of the evidence Marine Policy 23:47-69

Huang CJ, Lai H-p (2012) Estimation of stochastic frontier models based on multimodel inference Journal of Productivity Analysis 38:273-284 
Idda L, Madau FA, Pulina P (2009) Capacity and economic efficiency in small-scale fisheries: Evidence from the Mediterranean Sea Marine Policy 33:860-867

Innes J, Pascoe S (2008) Productivity Impacts of Veil Nets on UK Crangon Vessels Journal of Agricultural Economics 59:574-588

Jamnia AR, Mazloumzadeh SM, Keikha AA (2015) Estimate the technical efficiency of fishing vessels operating in Chabahar region, Southern Iran Journal of the Saudi Society of Agricultural Sciences 14:26-32 doi:https://doi.org/10.1016/j.jssas.2013.04.005

Jeon Y, Ishak Haji O, Kuperan K, Squires D, Susilowati I (2006) Developing country fisheries and technical efficiency: the Java Sea purse seine fishery Applied Economics 38:13 doi:https://doi.org/10.1080/00036840500400525

Jondrow J, Knox Lovell CA, Materov IS, Schmidt P (1982) On the estimation of technical inefficiency in the stochastic frontier production function model Journal of Econometrics 19:233-238 doi:https://doi.org/10.1016/0304-4076(82)90004-5

Kirkley J, Squires D, Strand IE (1995) Assessing technical efficiency in commercial fisheries: the mid-Atlantic sea scallop fishery American Journal of Agricultural Economics 77:686-697

Kirkley J, Squires D, Strand IE (1998) Characterising Managerial Skill and Technical Efficiency in a Fishery Journal of Productivity Analysis 9:145-160

Kompas T, Che TN, Grafton RQ (2004a) Technical efficiency effects of input controls: evidence from Australia's banana prawn fishery Applied Economics 36:1631 - 1641 doi:https://doi.org/10.1080/0003684042000218561

Kompas T, Che TN, Grafton RQ (2004b) Technical efficiency effects of input controls: evidence from Australia's banana prawn fishery Applied Economics 36:1631-1641

Kumbhakar SC (1990) Production frontiers, panel data, and time-varying technical inefficiency Journal of Econometrics 46:201-211 doi:https://doi.org/10.1016/0304-4076(90)90055$\underline{X}$

Lampe HW, Hilgers D (2015) Trajectories of efficiency measurement: A bibliometric analysis of DEA and SFA European Journal of Operational Research 240:1-21 doi:https://doi.org/10.1016/j.ejor.2014.04.041

Lindebo E, Hoff A, Vestergaard N (2007) Revenue-based capacity utilisation measures and decomposition: The case of Danish North Sea trawlers European Journal of Operational Research 180:215-227

Lokina RB (2009) Technical efficiency and the role of skipper skill in artisanal Lake Victoria fisheries Environment and Development Economics 14:497-519

Maravelias CD, Tsitsika EV (2008) Economic efficiency analysis and fleet capacity assessment in Mediterranean fisheries Fisheries Research 93:85-91

McDonald J (2009) Using least squares and tobit in second stage DEA efficiency analyses European Journal of Operational Research 197:792-798 doi:10.1016/j.ejor.2008.07.039

Meeusen W, Broeck JvD (1977) Efficiency Estimation from Cobb-Douglas Production Functions with Composed Error International Economic Review 18:435-444 doi: $10.2307 / 2525757$ 
Meeusen W, van Den Broeck J (1977) Efficiency Estimation from Cobb-Douglas Production Functions with Composed Error International Economic Review 18:435-444 doi: $10.2307 / 2525757$

Murillo-Zamorano LR (2004) Economic efficiency and frontier techniques Journal of Economic surveys 18:33-77

Ngoc QTK, Flaaten O, Kim Anh TN (2009) Efficiency of Fishing vessels affected by a Marine Protected Area - The case of small-scale trawlers and The Marine Protected Area in Nha Trang Bay, Vietnam. In: Integrated Coastal Zone Management. Wiley Blackwell, US. doi:https://doi.org/10.1002/9781444316285.ch15

Oliveira MM, Camanho AS, Walden JB, Gaspar MB (2016) Evaluating the influence of skipper skills in the performance of Portuguese artisanal dredge vessels ICES JOURNAL OF MARINE SCIENCE 73:2721-2728 doi:https://doi.org/10.1093/icesjms/fsw103

Orea L, Alvarez A, Paul CJM (2005) Modeling and measuring production process for a multispecies fishery: Alternative technical efficiency estimates for the Northern Spain hake fishery Natural Resource Modeling 18:183-213

Parmeter CF, Wan AT, Zhang X (2019) Model averaging estimators for the stochastic frontier model Journal of Productivity Analysis 51:91-103

Pascoe S, Coglan L (2002) The contribution of unmeasurable inputs to fisheries production: An analysis of technical efficiency of fishing vessels in the English Channel American $\begin{array}{llll}\text { Journal of Agricultural } & \text { Economics }\end{array}$ doi:https://www.jstor.org/stable/1244838

Pascoe S, Coglan L, Punt AE, Dichmont CM (2012a) Impacts of Vessel Capacity Reduction Programmes on Efficiency in Fisheries: The Case of Australia's Multispecies Northern Prawn Fishery Journal of Agricultural Economics 63:425-443

Pascoe S, Coglan L, Punt AE, Dichmont CM (2012b) Impacts of vessel capacity reduction programmes on efficiency in fisheries: The case of Australia's multi-species northern prawn fishery Journal of Agricultural Economics 63:425-443 doi:10.1111/j.14779552.2011.00333.x

Pascoe S, Hassaszahed P, Anderson J, Korsbrekke K (2003) Economic versus physical input measures in the analysis of technical efficiency in fisheries Applied Economics $35: 1699-1710$

Pascoe S, Herrero I (2004) Estimation of a composite fish stock index using data envelopment analysis Fisheries Research 69:91-105

Pascoe S, Hutton T, Coglan L, Nguyen VQ (2018) Implications of efficiency and productivity change over the season for setting MEY-based trigger targets Australian Journal of Agricultural and Resource Economics 62:199-216 doi:https://doi.org/10.1111/14678489.12244

Pascoe S, Hutton T, Coglan L, Quang VN (2017a) Implications of efficiency and productivity change over the season for setting MEY-based trigger targets Australian Journal of Agricultural and Resource Economics 59:1-18

Pascoe S, Hutton T, van Putten I, Dennis D, Plaganyi-Lloyd E, Deng R (2013) Implications of Quota Reallocation in the Torres Strait Tropical Rock Lobster Fishery: Implications of quota reallocation Canadian Journal of Agricultural Economics 61:335-352 
Pascoe S, Innes J, Courtney A, Kienzle M (2017b) Impact of reducing investment disincentives on the sustainability of the Moreton Bay prawn trawl fishery Fisheries Research 186:121-130

Pascoe S, Punt AE, Dichmont CM (2010) Targeting ability and output controls in Australia's multi-species Northern Prawn Fishery European Review of Agricultural Economics $37: 313-334$

Pascoe S, Tingley D (2007) Capacity and Technical Efficiency Estimation in Fisheries: Parametric and Non-parametric Techniques. In: Weintraub A, Romero C, Bjørndal T, Epstein R, Miranda J (eds) Handbook Of Operations Research In Natural Resources. Springer US, Boston, MA, pp 273-294

Pitt MM, Lee L-F (1981) The measurement and sources of technical inefficiency in the Indonesian weaving industry Journal of development economics 9:43-64

Quang VN, Pascoe S, Coglan L (2019) Implications of regional economic conditions on the distribution of technical efficiency: Examples from coastal trawl vessels in Vietnam Marine Policy 102:51-60

Quijano D, Salas S, Monroy-García C, Velázquez-Abunader I (2018) Factors contributing to technical efficiency in a mixed fishery: Implications in buyback programs Marine Policy 94:61-70 doi:https://doi.org/10.1016/j.marpol.2018.05.004

Ray SC (1999) Measuring scale efficiency from a translog production function Journal of Productivity Analysis 11:183-194

Rust S, Yamazaki S, Jennings S, Emery T, Gardner C (2017) Excess capacity and efficiency in the quota managed Tasmanian Rock Lobster Fishery Marine Policy 76:55-62 doi:https://doi.org/10.1016/j.marpol.2016.11.020

Schmidt P, Sickles RC (1984) Production frontiers and panel data Journal of Business \& Economic Statistics 2:367-374

Sharp BMH, Castilla-Espino D, García del Hoyo JJ (2004) Efficiency in the New Zealand rock lobster fishery: A production frontier analysis New Zealand Economic Papers 38:207218 doi:https://doi.org/10.1080/00779950409544403

Solís D, Agar JJ, del Corral J (2015a) IFQs and total factor productivity changes: The case of the Gulf of Mexico red snapper fishery Marine Policy 62:347-357

Solís D, Corral J, Perruso L, Agar JJ (2015b) Individual fishing quotas and fishing capacity in the US Gulf of Mexico red snapper fishery Australian Journal of Agricultural and Resource Economics 59:288-307

Solis D, del Corral J, Perruso L, Agar JJ (2014) Evaluating the Impact of Individual Fishing Quotas (IFQs) on the Technical Efficiency and Composition of the US Gulf of Mexico Red Snapper Commercial Fishing Fleet Food Policy 46:74-83

Solís D, Perruso L, del Corral J, Stoffle B, Letson D (2013) Measuring the initial economic effects of hurricanes on commercial fish production: the US Gulf of Mexico grouper (Serranidae) fishery Natural Hazards 66:271-289 doi:10.1007/s11069-012-0476-y

Squires D, Grafton RQ, Alam MF, Omar IH (2003) Technical efficiency in the Malaysian gill net artisanal fishery Environment and Development Economics 8:481-504

Squires D, Kirkley J (1999) Skipper skill and panel data in fishing industries Can J Fish Aquat Sci 56:2011-2018 doi:https://doi.org/10.1139/f99-135 
Susilowati I, Bartoo N, Omar IH, Jeon Y, Kuperan K, Squires D, Vestergaard N (2005) Productive efficiency, property rights, and sustainable renewable resource development in the mini-purse seine fishery of the Java Sea Environment and Development Economics 10:837-859 doi:https://doi.org/10.1017/S1355770X0500255X

Thanh PTDT, Huang HW, Chuang CT (2014) Finding a balance between economic performance and capacity efficiency for sustainable fisheries: Case of the Da Nang gillnet fishery, Vietnam Marine Policy 44:287-294

Thøgersen TT, Pascoe S (2014) Combining performance measures to investigate capacity changes in fisheries Applied Economics 46:57-69

Tingley D, Pascoe S (2005) Factors Affecting Capacity Utilisation in English Channel Fisheries Journal of Agricultural Economics 56:287-305

Tingley D, Pascoe S, Coglan L (2005) Factors affecting technical efficiency in fisheries: stochastic production frontier versus data envelopment analysis approaches Fisheries Research 73:363-376

Tsionas EG (2012) Maximum likelihood estimation of stochastic frontier models by the Fourier transform Journal of Econometrics 170:234-248

Valdmanis V (1992) Sensitivity analysis for DEA models: An empirical example using public vs. NFP hospitals Journal of Public Economics 48:185-205 doi:https://doi.org/10.1016/0047-2727(92)90026-C

Van Nguyen Q, Pascoe S, Coglan L (2019) Implications of regional economic conditions on the distribution of technical efficiency: Examples from coastal trawl vessels in Vietnam Marine Policy 102:51-60 doi:https://doi.org/10.1016/j.marpol.2019.01.016

Vestergaard N, Squires D, Kirkley J (2003) Measuring capacity and capacity utilisation in fisheries: the case of the Danish Gill-net fleet Fisheries Research 60:357-368 doi:https://doi.org/10.1016/S0165-7836(02)00141-8

Viswanathan KK, Omar IH, Jeon Y, Kirkley J, Squires D, Susilowati I (2001) Fishing Skill in Developing Country Fisheries: The Kedah, Malaysia Trawl Fishery Marine Resource Economics 16:293-314 doi:https://doi.org/10.1086/mre.16.4.42629339

Walden JB (2006) Estimating Vessel Efficiency Using a Bootstrapped Data Envelopment Analysis Model Marine Resource Economics 21:181-192

Yamazaki S, Resosudarmo BP, Girsang W, Hoshino E (2018) Productivity, Social Capital and Perceived Environmental Threats in Small-Island Fisheries: Insights from Indonesia Ecological Economics 152:62-75 doi:10.1016/j.ecolecon.2018.05.020

Zellner A, Kmenta J, Drèze J (1966) Specification and Estimation of Cobb-Douglas Production Function Models Econometrica 34:784-795 doi:10.2307/1910099 